\title{
A FORÇA DOS PRECEDENTES NO CPC/2015 E A ALTERAÇÃO DO ENTENDIMENTO PREDOMINANTE
}

\section{Leticia Squaris Camilo Men* Marcelo Negri Soares ${ }^{* *}$}

\section{RESUMO}

Muito embora o direito brasileiro seja considerado um sistema Civil Law, com a vigência do CPC/2015 pode-se afirmar que o direito brasileiro sofreu grande influência do sistema Common Law, principalmente quando se trata de precedentes. Por meio do método hipotético dedutivo, esta pesquisa demonstra, mediante breve conceituação, com busca às fontes doutrinárias e legais, as diferenças entre precedentes, súmulas e jurisprudência. Ademais, o artigo visa demonstrar que o distinguishing é a técnica adequada para verificar se o precedente se aplica ao novo caso, se deverá ser utilizado na fundamentação do magistrado ou se será superado.

Palavras-chave: Common Law; Civil Law; Precedentes; Distinguishing; Ratio Decidendi.

\section{THE FORCE OF THE PRECEDENTS IN CPC / 2015 AND THE CHANGE OF PREDOMINANT UNDERSTANDING}

\begin{abstract}
Although Brazilian law is considered a Civil Law system, with the validity of CPC / 2015 it can be stated that Brazilian law has been greatly influenced by the Common Law system, especially when it comes to precedents. Through the hypothetical deductive method, this research demonstrates, by brief conceptualization, searching doctrinal and legal sources, the differences between precedents and jurisprudence. Moreover, the article aims to demonstrate that distinguishing is the appropriate technique to verify whether the precedent applies to the new case, whether it should be used in the magistrate's reasoning or if it will be surpassed.
\end{abstract}

Keywords: Common Law; Civil law; Precedents; Distinguishing; Ratio Decidendi

\section{INTRODUÇÃO}

Cada país adota um sistema de normas próprios a serem utilizados em sua jurisdição,

\footnotetext{
* Graduada pelo Centro Universitário de Maringá - UniCesumar (2018). Mestranda em Ciências Jurídicas pela UniCesumar (2019-2020). Lattes: http://lattes.cnpq.br/0640274569134250.

** Professor e Pesquisador do Programa de Mestrado em Direito UniCesumar-PR. Pós-Doutorado pela UninoveSP (2017). Doutor pela PUC-SP (2013). Mestre pela PUC-SP (2005). Lattes: http://lattes.cnpq.br/8798303423669514
} 
sendo que tais sistemas podem sofrer influências. Os sistemas mais utilizados são o Civil Law e o Common Law.

No sistema brasileiro sempre houve predominância do sistema do Civil Law, dandose prioridade às normas como fonte do direito. Contudo, atualmente, percebe-se forte influência do Common Law, quando se trata de precedentes.

Isso porque o Common Law tem como fonte primária os entendimentos e decisões proferidas por tribunais superiores. O CPC/2015, assim, ao abordar a importância da aplicação dos precedentes, demonstra a sistemática do Common Law.

Com essas abordagens, o artigo visa conceituar os precedentes, tamanha sua importância e aplicabilidade com a vigência do Código Processual de 2015, diferenciandoos das súmulas e jurisprudências.

Também, verificar-se-á qual a técnica processual adequada para averiguar se o precedente é suficientemente igual ao novo caso a ser julgado, sua inaplicabilidade ao novo caso e, consequentemente, sua superação.

Assim, o intuito deste estudo é demonstrar a técnica do distinguishing, utilizada nas situações acima elencadas, bem como realizar uma proposta de melhoria da legislação que abordam os precedentes, como forma de auxiliar os aplicadores do direito e os leigos.

Para tanto, utilizou-se do método bibliográfico documental, para abordagem dos aspectos históricos, por meio de referências bibliográficas de qualidade, com doutrinas e produções científicas, com realce aos códigos e legislações. Adota-se, ainda, o método dedutivo, eis que extrai-se dos conceitos gerais de cada instituto, uma premissa menor, relacionando-os, com consideraçoes do pesquisador, propondo-se um acréscimo normativo.

\section{ASPECTOS HISTÓRICOS, ORIGENS E LEGISLAÇÃO ATUAL}

O sistema de precedentes é utilizado há muitos anos, embora não com essa terminologia, precipuamente no sistema anglo-saxão (Common Law), conforme será brevemente sintetizado neste capítulo.

Nos séculos XII e XIII na Europa Continental, formou-se o sistema Civil Law, por meio do Direito Romano estudado nas universidades. Essa sistemática se espalhou pelo globo terrestre por conta da colonização. 
O Civil Law compreende a legislação, ou seja, é nesse sistema que a legislação é a fonte primária do direito, sendo que as demais fontes, como doutrina e jurisprudência, são fontes secundárias e de menor importância, somente sendo utilizada quando há lacuna na legislação que impossibilita a resolução do conflito apenas pela lei.

No final do século XII e início do século XIII, o Direito Romano, que estava caindo no esquecimento, foi reavivado por intermédio do Imperador Justiniano I. O imperador, sentindo a necessidade de um corpo legislativo integrado e fortificado para a expansão do império, mandou criar uma legislação, selecionando as principais e mais importantes constituições dos impérios.

Essa compilação das principais legislações da época passou a se chamar de Corpus Juris Civilis, que significa "compilação de Direito Civil". Essa codificação renovou a busca pelo Civil Law, que passou a ser estudados nas universidades de toda a Europa, difundindo o sistema romano-germânico pelo mundo. Sua importância é inquestionável, conforme Alburn (1959, p.562):

The Corpus Juris Civilis or Body of Civil Law, was sired by the ancient laws of Solon, delivered by the Emperor Justinian and became the patriarch of existing codes of law. This compilation of Justinian consoidated Roman law for the Thousand years preceding him and formed the foundation of mosto $f$ the later legal codes throughout the world.

Muito embora o sistema romano-germânico tenha se espalhado pelo mundo, não foi influência nos povos ingleses. Talvez seja pelo fato de que os ingleses estavam fora da base continental, instalados em uma ilha, acabando por não serem dominados pelo Civil Law, criando um sistema próprio, o qual se denomina de sistema anglo-saxão.

O sistema anglo-saxão é composto pela Common Law, processo em que a legislação, a doutrina e a razão são fontes secundárias, priorizando-se os entendimentos e decisões dos tribunais hierarquicamente superiores. Assim, com uma decisão do tribunal superior, os demais tribunais e instâncias têm o dever de decidir casos análogos em conformidade com o que fora decidido anteriormente.

Menciona-se, contudo, que decisões proferidas por juízes de mesma hierarquia não vincula os demais da mesma escala. Isso se dá em razão da ratio decendi, que significa a 
causa de decidir ${ }^{1}$. É a razão de decidir que vincula os julgamentos posteriores de casos idênticos.

No Brasil, a divisão de poderes estabelece aqueles que criam as leis, os que as interpretam e os que executam. O processo de criação pelo Poder Legislativo advém da vontade do povo, de forma indireta, haja vista que na democracia é o povo quem elege os representantes do legislativo. Percebe-se que a criação do sistema brasileiro se fundamenta no Civil Law.

Não obstante, com o desenvolvimento da sociedade e do acesso à justiça, o Poder Judiciário passou a ficar abarrotado de processos, acabado por violar, assim, o princípio da celeridade processual e razoável duração do processo.

Com o fim de solucionar o problema, o Poder Judiciário passou, então, a receber influência da sistemática do Common Law, a qual as decisões superiores, além de persuadir os juízes de instâncias inferiores, passaram também a vinculá-los, com o fim de uniformizar as decisões em busca da maior segurança jurídica.

Essa nova sistemática adotada, ainda pendente de muitas críticas, dá ao magistrado a possibilidade de flexibilizar a lei, adotando posicionamento que poderá se tornar vinculante às demais decisões de instâncias inferiores. Dentre as mencionadas críticas, PICARDI e NUNES (2011, p.106- 107):

\begin{abstract}
Nesse contexto, o Judiciário brasileiro, nem mediante um esforço incomensurável de seus órgãos, conseguiria ser "virtuoso" em face das exigências de produtividade numérica e de rapidez procedimental máxima. Com Waldron, devemos perceber que "construímos (...) um retrato idealizado do julgar e o emolduramos junto com o retrato de má fama do legislar"35 e, em face disso, precisamos repensar nossa situação jurídica e os discursos românticos da virtude e sensibilidade de nossos decisores, sob pena de com o rótulo de um idílico "ativismo judicial" se implementar uma verdadeira juristocracia. Infelizmente, em face desses e de outros fatores, o sistema processual brasileiro costuma trabalhar com uma eficiência quantitativa, impondo mesmo essa visão neoliberal (NUNES, 2008) de alta produtividade de decisões e de uniformização superficial dos entendimentos pelos tribunais,36 mesmo que isso ocorra antes de um exaustivo debate em torno dos casos, com a finalidade de aumentar a estatística de casos "resolvidos".
\end{abstract}

\footnotetext{
${ }^{1}$ Ratio decendi significa a razão de decidir, sendo fundamentos cruciais da decisão. De acordo com Marinoni: constitui uma generalização das razões adotadas como passos necessários e suficientes para decidir um caso ou as questões de um caso pelo juiz. Em uma linguagem própria à tradição romano-canônica, poderíamos dizer que a ratio decidendi deve ser formulada por abstrações realizadas a partir da justificação da decisão judicial. Importante abordar sobre a Obter dictum, que significa "dito de passagem”. Ou seja, aquilo que é proferido em um julgamento, porém que não é necessário para a solução da lide.
} 
Buscando melhorar o sistema processual brasileiro, criou-se o CPC/2015, que abarcou a questão de precedentes (cujos conceitos e natureza jurídica será trabalhado no capítulo seguinte) e de decisões vinculativas, como forma de uniformizar as decisões, buscando a segurança jurídica, bem como para solucionar a morosidade do judiciário.

\section{PRECEDENTES: CONCEITO E NATUREZA JURÍDICA.}

Embora o CPC/2015 tenha dado grande importância aos precedentes, não cuidou de trazer qualquer conceito do que seriam "precedentes", nem cuidou de distingui-los das súmulas e da jurisprudência.

Conceitualmente, precedente é uma decisão, bem fundamentada, proferida em determinada lide, que é utilizada, posteriormente, em casos idênticos. Para Câmara (2016, p. 428), sempre que uma decisão posterior se fundamentar em uma decisão anterior, esta se considera um precedente.

Para Didier Junior (2009, p. 381), precedente é “a decisão judicial tomada à luz de um caso concreto, cujo núcleo essencial pode servir como diretriz para o julgamento posterior de casos análogos."

Importante salientar que precedente é sempre uma decisão judicial, porém nem toda decisão judicial é considerada um precedente, pois são necessários elementos para que uma decisão seja revestida como precedente.

Embora haja grande preocupação com as decisões conflitantes, devido às constantes mudanças de entendimento dos Tribunais, diferentemente dos julgamentos de recursos repetitivos, os precedentes não têm o escopo de solucionar questões de massa, visto que o núcleo é a identidade dos casos a serem julgados, alternando-se apenas as partes.

Não obstante o objetivo de precaver decisões conflitantes, a vinculação dos precedentes também acaba por auxiliar a morosidade dos processos, devido ao número excessivo de lides. Sobre o tema, WAMBIER e WAMBIER (2016, p. 484):

Basta, apenas, recordar que a valorização da jurisprudência, no sentido lato, gera: a) possibilidade de se criarem institutos que levam à aceleração do procedimento; b) a que haja mais credibilidade em relação ao Poder Judiciário; c) a uma progressiva diminuição da carga de trabalho do Judiciário, já que a desuniformidade da jurisprudência a possibilidade, que existe sempre, de que haja uma "virada" 
estimula não só o ato de recorrer, como também a própria propositura de novas ações.

Feito a conceituação, importante salientar que não se confunde precedente com jurisprudência, que é aplicação reiterada de um precedente. O precedente é, portanto, unitário, enquanto a jurisprudência são decisões que se utilizam reiteradamente do precedente. Para Soares, Couto e Costa (2018, p. 562):

Por conseguinte, para a formação de uma jurisprudência, é essencial a união de três fatores distintos, quais sejam, a existência de múltiplos julgados, a harmonia entre os entendimentos neles contidos, bem como que sejam proferidos em determinado recorte temporal, haja vista que somente a estabilidade do decurso do tempo é que pode conferir força persuasiva à jurisprudência.

Não se confunde precedente, ainda, com súmulas. Estas são, suscintamente, as ideias principais de uma tese aplicada reiteradamente pelo tribunal, solucionando casos semelhantes, de forma resumida (WAMBIER, 2016, p. 486). Ainda sobre as súmulas, Câmara (2016, p. 431):

O enunciado de súmula, portanto, não é um precedente. Trata-se de um extrato de diversos pronunciamentos, isto é, algo que se extrai de diversas decisões sobre a mesma matéria. Tais decisões podem, até mesmo, basear-se em fundamentos determinantes distintos, mas em todas elas se identificou a mesma conclusão [...].

Com essa breve conceituação dos precedentes e sua diferenciação da jurisprudência e das súmulas, importante explicar, brevemente, acerca da natureza jurídica desse instituto.

Há duas teorias que cuidam de definir a natureza jurídica do precedente judicial, quais sejam: constitutiva ou declaratória. A primeira defende que o magistrado possui autoridade para interpretar a lei de acordo com sua vontade, haja vista a impossibilidade de a lei dispor sobre todas as situações possíveis do caso concreto, necessitando da atuação do magistrado.

Essa teoria é baseada no Common Law, cujo direito é formado pela jurisprudência em sua maior parte e não pela lei. Assim, a natureza constitutiva se refere à criação da lei pelo juiz.

A segunda teoria, por sua vez, justifica que o juiz deve apenas declarar a lei e não cria-la, visto que a criação decorre de um processo legislativo e não judicial. Muito embora haja a discussão sobre sua natureza jurídica, fato é que qualquer texto admite interpretação e, 
como mencionado anteriormente, a lei não prevê de forma absoluta todas as hipóteses, ficando o magistrado com a incumbência de superar as lacunas do direito, que acaba passando por um processo criativo.

\section{PRINCÍPIO DA MOTIVAÇÃO DAS DECISÕES}

Neste capítulo será abordado o princípio da motivação das decisões judiciais, bem como sua importância dentro dos elementos obrigatórios das sentenças. Esse princípio é fundamental para se efetivar a formação de um precedente, pois, como estudado anteriormente, é por meio da ratio decidendi que possibilita a utilização de uma decisão para fundamentar casos futuros.

O dever de fundamentação da decisão surge como forma de frear decisões arbitrárias do Poder Judiciário, que impede que as partes litigantes tenham condições de confeccionar eventual recurso para efetivação de seu direito. Esse tipo de decisão viola os princípios da ampla defesa e do duplo grau de jurisdição.

Assim, a Constituição Federal brasileira, em seu artigo 93, inciso IX dispõe que todas as decisões decorrentes de julgamento do Poder Judiciário serão fundamentadas, sob pena de nulidade. A garantia constitucional de fundamentação das decisões é corroborada com o art. 11 do CPC/2015, que expressou a literalidade do texto constitucional.

Verifica-se, portanto, que o princípio da motivação das decisões é mais que um mero princípio, é uma regra, um dever legal, uma garantia constitucional às partes, conforme explica Lucca (2016, p. 87) "O dever imposto aos juízes de motivar suas decisões é uma regra jurídica, independentemente dos critérios utilizados para distinguir regras de princípios. Uma singela e breve análise lógico-conceitual, como a que foi feita acima, afasta quaisquer dúvidas a respeito dessa conclusão".

Assim, antes de conceituar o dever de fundamentação, será abordado os elementos essenciais das sentenças e o que não é considerado como decisão fundamentada, para, então, abordar o efetivo significado do princípio.

Inicialmente, a sentenças são compostas por três elementos essenciais, quais sejam: relatório, fundamentação e dispositivo. O relatório é o elemento inicial, quando o magistrado fará uma síntese do processo, narrando o caso, identificando as partes, mencionando os pedidos e as principais ocorrências processuais até o momento. 
Posteriormente, dá-se início ao segundo elemento, a fundamentação é o componente que o magistrado conduz o direito ao caso, expondo as razões legais de sua decisão. $\mathrm{O}$ art. $489, \S 1^{\circ}$ do CPC, inovação no referido código, aborda o que não se considera fundamentação, nos seguintes termos:

\footnotetext{
Art. 489. São elementos essenciais da sentença:

$\S 1^{\circ}$ Não se considera fundamentada qualquer decisão judicial, seja ela interlocutória, sentença ou acórdão, que:

I - se limitar à indicação, à reprodução ou à paráfrase de ato normativo, sem explicar sua relação com a causa ou a questão decidida;

II - empregar conceitos jurídicos indeterminados, sem explicar o motivo concreto de sua incidência no caso;

III - invocar motivos que se prestariam a justificar qualquer outra decisão;

IV - não enfrentar todos os argumentos deduzidos no processo capazes de, em tese, infirmar a conclusão adotada pelo julgador;

V - se limitar a invocar precedente ou enunciado de súmula, sem identificar seus fundamentos determinantes nem demonstrar que o caso sob julgamento se ajusta àqueles fundamentos;

VI - deixar de seguir enunciado de súmula, jurisprudência ou precedente invocado pela parte, sem demonstrar a existência de distinção no caso em julgamento ou a superação do entendimento.
}

De fato, o dispositivo tem o escopo de trazer maior qualidade à fundamentação dos magistrados e, também, conforme mencionado, visa a proteção da garantia constitucional, possibilitando a ampla defesa e o segundo grau de jurisdição. Por fim, a sentença será composta pelo dispositivo, ocasião em que o magistrado discorrerá sobre sua conclusão, prolatando o resultado dela decorrente.

Embora as três partes sejam requisitos essenciais da sentença, o foco da análise deste estudo é a fundamentação. Isso porque é nesta etapa em que se verificará o desenvolvimento do raciocínio do magistrado, com a exposição das justificativas da aplicação (ou não) de determinada disposição legal, que dará amparo à decisão final.

O princípio da motivação, que adentra ao elemento da fundamentação da sentença, de acordo com Bueno (2019, p. 60), é o dever de explicar, fundamentar e justificar as decisões proferidas, uma vez que o magistrado aplica a norma de acordo com sua interpretação e, para que haja eventual correção, se faz necessário entender a razão que levou o julgador a decidir de determinada forma e não de outra.

Ademais, Hartmann (2019, p. 12) discorre que o princípio se justifica para que o magistrado não profira decisões arbitrárias, decidindo da forma que lhe convém sem indicar os motivos que o levaram a decidir daquele modo. Como exposto anteriormente, o autor 
acrescenta que o princípio se revela crucial para que as partes tenham argumentos para expor as razões de seu inconformismo em eventual recurso.

Por óbvio, a necessidade de uma fundamentação com qualidade também se faz necessária para que o processo tenha uma relevância para a formação de um precedente judicial. Kaufman (2010, p.6) explica que uma decisão judicial envolve diferentes considerações, de acordo com cada caso: "Indeed, in a way, a subtheme of Cardozo's lectures is that judicial decision-making involves a nuanced approach among different considerations, any one of wich may be dominant with respect to a particular issue or in the contexr of particular facts".

Isso significa que é indispensável a exposição dos motivos que o levaram a decidir daquela forma, possibilitando, assim, que a decisão seja considerada um precedente. Nas palavras de Soares, Couto e Costa (2018, p. 565):

\footnotetext{
Ademais, o juiz, a fim de conferir legitimação a sua atuação interpretativa e criativa, tem a obrigação de cumprir satisfatoriamente o dever constitucional da fundamentação. Isso porque a ratio decidendi, enquanto fundamento jurídico que sustenta uma decisão judicial, para ser hábil a vincular o julgamento de questões idênticas no futuro, deve ser clara e transparente. E isso, a nosso ver, só poderá ser vislumbrado por meio de um adequado processo de fundamentação, vetor que será primordial para a formação dos precedentes judiciais, conforme melhor se explicita nas linhas que seguem.
}

Ante todo o exposto, verifica-se a importância do princípio da motivação das decisões, seja para formação de precedentes, seja para garantir outros princípios. Fato é que a fundamentação das decisões judiciais passou a ser crucial para validação do entendimento do magistrado, concebido em suas decisões.

\section{Distinção DE UM PRECEDENTE PARA VERIFICAR A INAPLICABILIDADE NO CASO.}

Neste capítulo será abordado sobre a técnica da distinção do precedente, comumente chamado de distinguishing, que é o meio adequado para demonstrar a não aplicação do precedente no caso. 
Ademais, a técnica se demonstra deveras importante, haja vista que os tribunais têm restringido inúmeros recursos por conta dos entendimentos engessados, firmados nas teses jurídicas já firmadas.

Salienta-se que um precedente não nasce sendo um precedente. O magistrado, ao julgar um caso e proferir uma decisão, não sabe que sua decisão será um precedente (ainda que assim espere). Para se tornar um precedente, essa decisão precisa ser perfeitamente fundamentada, com argumentos tão fortes que possam ser utilizados posteriormente por outro magistrado e, somente então, é formado o precedente.

Não obstante, um precedente, embora necessite ter certa similaridade com o novo caso a ser julgado, não requer identidade de todos os fatos e aplicação de todo o direito. Para Cunha e Macedo (2015, p.11), o magistrado deve verificar em que medida o caso e o precedente se subsumem, estabelecendo analogias e contra-analogias, a qual ele define como distinguishing, que serão fatores para averiguar a aplicabilidade do precedente ou não.

De fato, ao lidar com a utilização de um precedente, as comparações são inevitáveis. Assim, diante das constatações dos pontos similares e dos pontos divergentes, averiguar-se-á se os casos são correlatos o suficiente para terem consequências iguais, ou distintas o suficiente para terem consequências diferentes. Cunha e Macedo (2015, p. 12) ainda explicam:

Em outras palavras, no raciocínio por precedentes, a analogia e o distinguishing (disanalogie ou contra-analogia) colocam-se como técnicas que, conquanto situadas em extremos opostos, fundam-se essencialmente na realização de comparações, definindo a aplicabilidade de determinado precedente ao caso concreto, à luz da coerência e da integridade do Direito.

Distinguishing é, portanto, uma técnica que o magistrado utilizará quando estiver diante um precedente que não se enquadra suficientemente no caso novo, por meio de comparações dos fatos, qualidades, situações, etc. Assim, verificado que os casos não conferem o mesmo resultado, romperá com o precedente e proferirá seu próprio julgamento.

Não obstante, a inaplicabilidade de um precedente não lhe questiona sua validade. $\mathrm{O}$ precedente continua a ser eficaz e legítimo, permanecendo sua aplicabilidade em outros casos. Porém, se o magistrado utilizar um precedente quando os fatos dos casos não se subsumem à mesma ratio decidendi, estará violando o princípio da isonomia. 
Vale frisar que, inclusive a inaplicabilidade do precedente ao caso, por meio do distinguishing, deve ser muito bem fundamentado pelo magistrado, possibilitando que as partes tenham acesso às razões que levaram ao não enquadramento do caso no precedente.

Deste modo, quando os fatos do caso novo não se equivaler à ratio decidendi que originou o precedente, este não poderá ser utilizado pelo magistrado, devido à distinção entre os casos, o que se chama de distinguishing.

\section{VALIDADE DOS CONCEITOS OBTER DICTUM PARA ALCANÇAR O NÚCLEO DO PRECEDENTE QUE VINCULA OS CASOS FUTUROS.}

A terminologia "obter dictum” significa os fragmentos dispensáveis de uma decisão, ou seja, que não constituem premissas fundamentais na decisão, como a ratio decidendi. Contudo, não é uma regra que todos os fundamentos que não foi dada muita atenção na decisão é considerado obter dictum. Deve-se atentar a um fundamento que não foi devidamente discutido quando, na verdade, deveria ter sido, tratando-se, assim, de omissão do julgado.

Ao proferir uma decisão, o magistrado emana o percurso de seu raciocínio jurídico ao fazer a subsunção da norma ao caso, aplicando o direito. Trata-se grande complexidade a exposição de forma simplificada do enquadramento da norma à situação que se está julgando, explicando os motivos que assim o levaram a decidir e os motivos por ele não ter decidido de outra forma.

Dentro de uma decisão, contudo, há diversas modalidades de considerações e fundamentos, cada um com certo grau de relevância dentro do julgamento do caso. Alguns argumentos que não se referem ao pedido ou à causa de pedir e que não foram abordados pelas partes durante o trâmite processual, são fundamentos obiter dicta (plural do obiter dictum).

Sobre tais pronunciamentos, GW Paton e G Sawer (1947):

Little discussion of this problem is found in the authorities, whether judicial opinions or learned writings. Professor Goodhart, however, says: 'How do we determine the principle of a case in wich there are several opinions wich agree as to the result, but differ in the material facts on wich they are based? In such na aevent 
the principle of the case is limited to the sum of all the facts held to be material by the various judges [...].

E para Marinoni (2010, p.28):

\begin{abstract}
Mais difícil, sem dúvida, é isolar o fundamento que, independentemente de ter sido alegado e discutido pelos juízes, era desnecessário à tomada da decisão. É certo que, quando um fundamento é desnecessário para se chegar à solução de dada questão, em regra ele não é tomado a sério e efetivamente discutido pelos juízes, caracterizando-se facilmente, desta forma, como obiter dictum.
\end{abstract}

É possível perceber que embora o conceito de obiter dictum esteja interligado ao conceito de ratio decidendi, não se é dada a mesma importância aos dois. Isso porque há diversas pesquisas e escritos sobre este, mas quase não se explora sobre conceituação e aplicação daquele.

O obiter dictum acaba sendo tudo aquilo que não se enquadra como ratio decidendi, não lhe sendo dada a importância devida. Ora, um obiter dictum, embora não sendo o centro do fundamento, também é um argumento elaborado pelo magistrado e pode, embora não com força vinculante, ser utilizado também em outras decisões, pois também têm força persuasiva.

Portanto, embora tenham sua importância, os fundamentos obiter dictum não possuem força suficiente para se alcançar o núcleo do precedente que vincula casos futuros, visto que não vinculam a decisão (BUSTAMANTE, 2018 p. 714). Contudo, como visto no parágrafo anterior, tais fundamentos podem ser utilizados em outras decisões por sua força persuasiva, sendo que, nesta decisão nova, pode se transformar em uma ratio decidendi e, assim, alcançar o núcleo de um novo precedente que vinculará casos futuros.

\title{
6. QUAL A TÉCNICA PROCESSUAl PARA VERIFICAR SE O CASO EM JULGAMENTO É SUFICIENTEMENTE IGUAL AO QUE INFORMOU O PRECEDENTE?
}

Como visto no capítulo 4, a técnica de distinguishing é utilizada para demonstrar a não aplicação de um precedente no caso que se está julgando. Isso porque, de acordo com Amaral (2016, p. 586), o CPC/2015 concedeu aos precedentes um caráter vinculativo. Ou seja, o magistrado é obrigado a utilizar os precedentes, podendo dele se desvincular apenas ao constatar alguma divergência significativa com o caso novo. 
Utilizar-se-á, assim, de algumas técnicas para verificar se o precedente se enquadra ao caso novo. No sistema brasileiro, além da técnica do distinguishing, que é o confronto, há a técnica da superação, chamada de overruling, mas que não será abordada neste estudo.

Pois bem, para se utilizar um precedente, é necessário averiguar se há semelhanças o suficiente entre ele e o caso novo. A técnica de comparação será utilizada para, lado a lado, se verificar os pontos em comum e os pontos divergentes. Após o cotejo inicial, com análise dos fatos, será necessário verificar a norma jurídica utilizada no precedente, identificando o ratio decidendi.

Para verificar se o caso em julgamento é suficientemente igual ao que informou o precedente, deve-se mergulhar a fundo nos fatos e fundamentos do precedente, comparando-o minuciosamente ao caso novo. Somente assim será possível identificar se há relação entre os fatos elementares e os fundamentos utilizados como base (ratio decidendi) no precedente.

Somente após essa comparação, o magistrado deverá fundamentar sua decisão, demonstrando os motivos de eventual não aplicação do precedente. Lourenço (2012, p. 259) defende que o magistrado, diante da hipótese de poder verificar a aplicação ou não do precedente ao caso, não estaria engessado, caindo por terra as alegações de que ele seria um "robô", sem discricionariedade de não aplicação do precedente.

Deste modo, a técnica adequada para verificar se o caso em julgamento é suficientemente igual ao que informou o precedente é o distinguishing, que pode ser utilizado tanto pelo magistrado, para fundamentar que o precedente não se aplica ao caso, quanto pela parte, para demonstrar, por meio de recurso, que a decisão não deveria ter se utilizado dos fundamentos do precedente, porque há algum fator primordial que não aplica a ratio decidendi do precedente no caso novo.

A técnica é, portanto, imprescindível para evitar o engessamento das decisões dos magistrados, e também para possibilitar que as partes possam se utilizar de eventual recurso para demonstrar a inaplicabilidade do precedente ao caso, dando maior segurança jurídica e menos arbitrariedade nas decisões.

\section{PROPOSTA DE LEGE FERENDA PARA MELHORIA DO SISTEMA LEGISLADO.}


O CPC/2015, mesmo após anos de discussão para sua formulação, mesmo sendo um código recente, apresenta falhas, como qualquer outro sistema legal existente. O código processual civil teve início com Projeto de Lei n 8.406 no ano de 2010 e, após anos de discussões, passou a vigorar em março de 2016, revogando o antigo código de 1973.

Os precedentes no $\mathrm{CPC} / 2015$ são mencionados no art. 926 , $§ 2^{\circ}$, porém de forma muito breve. Como exposto anteriormente, o CPC não traz previsão conceitual de um precedente, nem o difere das jurisprudências e súmulas vinculantes.

Portanto, acredita-se que seja uma falha no sistema processual civil brasileiro a falta de conceituação, visto que a lei é para todos: para doutores, para magistrados, para advogados, mas também para leigos, que podem não ter conhecimento do que seria um precedente.

Muito embora a própria terminologia já traga uma sugestão do conceito de precedente, é muito comum, inclusive em bacharéis em direito, a confusão dos precedentes com jurisprudência. Daí a importância de uma conceituação, que a lei não abordou.

Deste modo, como proposta de lege ferenda, sugere-se um acréscimo de parágrafos no art. 926 do CPC, com a conceituação de precedente, diferenciando-o da jurisprudência, com os seguintes dizeres: Art. $926, \S 3^{\circ}$ Considera-se precedente a decisão judicial de um caso anterior, cujas razões de decidir possam ser utilizadas para fundamentar decisão de um caso novo, o que não se confunde com jurisprudência, que são decisões reiteradas de certo tribunal.

\section{CONCLUSÃO}

O direito brasileiro sofreu influências predominantemente do sistema do Civil Law, cuja fonte primária é a legislação. Contudo, com o advento do CPC/2015, percebe-se a grande influência do sistema anglo-saxão, composto pela Common Law, principalmente no que tange à questão dos precedentes.

A utilização dos precedentes, além de dar maior celeridade aos processos, também visa dar maior segurança jurídica, com a uniformização das decisões. Contudo, há na doutrina brasileira muitas críticas pelo fato de que essa sistemática acaba por dar ao magistrado a possibilidade de flexibilizar a lei, por meio de sua interpretação. 
De mais a mais, o precedente, conceitualmente, é uma decisão proferida em uma lide, perfeitamente fundamentada, que é utilizada por outro julgador em lide diversa, solucionando casos semelhantes. Essa utilização é possível após análise da ratio decidendi. Ou seja, se ambos os casos subsumirem à mesma ratio decidendi, então é cabível a utilização do precedente. Daí a importância que as decisões atendam ao princípio da motivação das decisões, cabendo ao magistrado o dever de fundamentar adequadamente suas decisões.

Além disso, esse princípio, considerado mais que um princípio, mas também uma garantia constitucional, também tem por escopo garantir às partes o duplo grau de jurisdição, eis que com acesso aos motivos que levaram à decisão proferida, terá possibilidade de recorrer, se assim achar conveniente.

Também é de suma importância as decisões bem fundamentadas para que um precedente possa ser superado. Tal superação se dá por meio da técnica denominada de distinguishing, quando o magistrado, diante do caso concreto, irá comparar o caso novo, minuciosamente, com o precedente, averiguando se ambos são suficientemente idênticos, ou se há peculiaridades em que o precedente não se enquadrará, proferindo-se, assim, decisão divergente.

Muito embora os precedentes estejam se popularizando, compreende-se que a legislação é deficitária no que se refere ao tema, haja vista que sequer aborda a conceituação da nomenclatura, nem o diferencia de súmulas e jurisprudências, levando leigos e até juristas à erros técnicos. Assim, o artigo faz uma proposta de melhoria do artigo processual que dispõe sobre os precedentes com sua breve conceituação. Acredita-se que a proposta traria grande melhoria no compreendimento do direito.

\section{REFERÊNCIAS}

ALBURN, Cary R. Corpus Juris Civilis: A Historical Romance. American Bar Association Journal 45, no. 6 (1959): 562-642. http://www.jstor.org/stable/25720817.

BUENO, Cassio Scarpinella. Manual de direito processual civil. volume único. 5. ed. São Paulo: Saraiva, 2019. 
BUSTAMANTE, Thomas da Rosa de. Obiter dicta abusivos: esboço de uma tipologia dos pronunciamentos judiciais ilegítimos. Rev. direito GV, São Paulo, v. 14, n. 2, p. 707745, ago. 2018.

Disponível

em

$<$ http://www.scielo.br/scielo.php?script=sci_arttext\&pid=S1808-

$24322018000200707 \& \operatorname{lng}=$ pt\&nrm=iso>.

acessos

em 15

jul. 2019. http://dx.doi.org/10.1590/2317-6172201827.

CÂMARA, Alexandre Freitas. O Novo Processo Civil Brasileiro. 2. ed. São Paulo: Atlas. 2016.

CUNHA, Leonardo Carneiro da; MACÊDO, Lucas Buril de; ATAÍDE JR, Jaldemiro Rodrigues de (org.). Precedentes judiciais no NCPC. Coleção Novo CPC e novos temas. Salvador: Juspodivm, 2015.

DIDIER JÚNIOR, Fredie. Curso de direito processual civil: teoria geral do processo e processo de conhecimento. 11. ed. Salvador: JusPodium, 2009.

GW Paton e G Sawer. Ratio Decidendi and Obiter Dictum in Appellate Courts. LQ Rev., 1947 - HeinOnline.

HARTMANN, Rodolfo Kronemberg. Curso completo do novo processo civil. 5 ed. Niterói: Impetus, 2019.

KAUFMAN, Andrew L.; CARDOZO, Benjamin N. The Nature of the Judicial Process. U.S: Quid Pro Books, 2010.

LOURENÇO, Haroldo. Precedente Judicial Como Fonte Do Direito: Algumas Considerações Sob A Ótica Do Novo CPC. Revista Da AGU [Online], Volume 11 Número 33 (30 September 2012).

LUCCA, Rodrigo Ramina de. O dever de motivação das decisões judiciais: Estado de direito, segurança jurídica e teoria dos precedentes. $2^{\text {a }}$ ed. ver. e atual. São Paulo: Jus Podivm, 2016. 
MARINONI, Luiz Guilherme; et. al.. Novo código de processo civil comentado. 1.ed. São Paulo: RT, 2015.

MARINONI, Luiz Guilherme. Elaboração dos conceitos de ratio decidendi (fundamentos determinantes da decisão) e obiter dictum no direito brasileiro. A força dos precedentes: estudos dos cursos de mestrado e doutorado em direito processual civil da UFPR, v. 2, p. 599$630,2010$.

PICARDI, Nicola; NUNES, Dierle. Revista de Informação Legislativa / Ano 1, n. 1 (mar. 1964)- . - Brasília: Senado Federal, Subsecretaria de Edições Técnicas, 1964.

SOARES, Marcelo Negri; COUTO, Monica Bonetti; COSTA, Jessica Chaves. Dever de fundamentação e precedentes no novo CPC: uma análise à luz do modelo constitucional de processo. Revista Eletrônica do Curso de Direito da UFSM, Santa Maria, RS, v. 13, n. 2, p. 554-576, ago. 2018. ISSN 1981-3694. Disponível em: < https://periodicos.ufsm.br/revistadireito/article/view/29302 >. Acesso em: dia mês. ano. doi: http://dx.doi.org/10.5902/1981369429302.

WAMBIER, Luiz Rodrigues; WAMBIER, Teresa Arruda Alvim. Temas Essenciais do Novo CPC: Análise das principais alterações do sistema processual civil brasileiro, de acordo com a Lei 13.256/2016. São Paulo: Revista dos Tribunais. 2016 